Review

\title{
Mechanistic Aspects of Factors Affecting Pitting Corrosion of Metallic Materials for Marine Application: A Review Paper
}

\author{
Shicheng Wei ${ }^{*}$, Hongyi Su \\ National Key Laboratory for Remanufacturing, Army Academy of Armored Forces, Beijing 100072, \\ China \\ *E-mail: wsc33333@163.com
}

doi: $10.20964 / 2019.04 .02$

Received: 24 October 2018 / Accepted: 24 December 2018 / Published: 10 March 2019

\begin{abstract}
Seawater as an electrolyte makes metals and alloys suffer from corrosion deterioration. Among various corrosion forms, pitting corrosion is extremely hazardous for marine structures. It degrades the performance of metal materials and reduces the service life of equipment and facilities. The theory concerning pitting corrosion has gained a certain process. However, its behavior and mechanism in some special environments such as deep-sea environment are still not fully understood. Hence, a review involving these issues is a need. This paper summarizes the current progress in aspects of pit mechanism including pit initiation, metastable pit, propagation of pit and its affecting factors. The focus is the influencing mechanism of three interesting factors on metal corrosion covering passive film, hydrostatic pressure and mechanical load.
\end{abstract}

Keywords: Pitting corrosion; Passive film; Hydrostatic pressure; Mechanical load

\section{$\underline{\text { FULL TEXT }}$}

(C) 2019 The Authors. Published by ESG (www.electrochemsci.org). This article is an open access article distributed under the terms and conditions of the Creative Commons Attribution license (http://creativecommons.org/licenses/by/4.0/). 